\title{
Polypyrimidine-tract-binding protein is a component of the HCV RNA replication complex and necessary for RNA synthesis
}

\author{
Hideki Aizaki ${ }^{1,2}$, Keum S. Choi ${ }^{1}$, Minyi Liu ${ }^{1}$, Yi-jia Li $^{1}$ \& Michael M.C. Lai ${ }^{1,3, *}$ \\ ${ }^{1}$ Department of Molecular Microbiology and Immunology, University of Southern California, Keck School of \\ Medicine, 2011 Zonal Ave., HMR-503, Los Angeles, CA, 90033, California, USA; ${ }^{2}$ Department of Virology \\ II, National Institute of Infectious Diseases, Shinjuku-ku, Tokyo, 162-8640, Japan; ${ }^{3}$ Institute of Molecular \\ Biology, Academia Sinica, Nankang, 115, Taiwan
}

Received 16 February 2006; accepted 10 April 2006

(c) 2006 National Science Council, Taipei

Key words: hepatitis $\mathrm{C}$ virus, $\mathrm{PTB}$, RNA replication, lipid rafts

\begin{abstract}
The machinery for hepatitis $\mathrm{C}$ virus (HCV) RNA replication is still poorly characterized. The relationship between HCV RNA replication and translation is also not clear. We have previously shown that a cellular protein polypyrimidine-tract-binding protein (PTB) binds to HCV RNA at several different sites and modulates HCV translation in several ways. Here we show that PTB also participates in RNA replication. By bromouridine triphosphate (BrUTP) labeling and confocal microscopy of cells harboring an HCV replicon, we showed that the newly synthesized HCV RNA was localized to distinct structures in the cytoplasm, which also contain PTB. Membrane flotation analysis demonstrated that a fraction of cytoplasmic PTB was associated with a detergent-resistant membrane (DRM) structure consisting of lipid rafts, which also contained HCV nonstructural proteins and the human vesicle-associated membrane proteinassociated protein (hVAP-33). PTB in the DRM was resistant to protease digestion, but became sensitive after treatment with the raft-disrupting agents. PTB in the DRM consisted of multiple isoforms and the brain-specific paralog. By using small interfering RNA (siRNA) of PTB, we showed that silencing of the endogenous PTB reduced the replication of HCV RNA replicon. In a cell-free, de novo HCV RNA synthesis system, HCV RNA synthesis was inhibited by anti-PTB antibody. These studies together indicated that PTB is a part of the HCV RNA replication complex and participates in viral RNA synthesis. Thus, PTB has dual functions in HCV life cycle, including translation and RNA replication.
\end{abstract}

\section{Introduction}

Hepatitis $\mathrm{C}$ virus $(\mathrm{HCV})$ is a major causative agent of chronic hepatitis, liver cirrhosis, and hepatocellular carcinoma. Blood screening based on the cloned HCV genome and its gene products has reduced significantly the blood-borne HCV transmission [1-3]. However, detailed studies of $\mathrm{HCV}$ (for example, virus replication, pathogenicity, and natural history of $\mathrm{HCV}$ ) have been greatly ham-

*To whom correspondence should be addressed. Fax $+1-323-$ 442-1721, E-mail: michlai@usc.edu pered by the lack of efficient in vitro culture systems of $\mathrm{HCV}$ infection.

Viral replication often requires the participation of host factors, which interact with viral RNA and/ or viral proteins [4]. In the case of HCV, several RNA-binding proteins, including La, NS1-associated protein 1 (NSAP1), and polypyrimidine tractbinding protein (PTB), have been shown to bind to the 5 '-end of HCV RNA and regulate HCV internal ribosome entry site (IRES)- mediated translation [5-7]. In addition, several cellular proteins have been shown to bind HCV nonstructural (NS) proteins; for example, human vesicle-associated membrane 
protein-associated protein of $33 \mathrm{kDa}$ (hVAP-33) was reported to bind to NS5A and NS5B proteins, and recruited them to the membrane to form the HCV replication complex (RC) [8, 9]. This cellular protein is important for HCV RNA replication.

PTB, in particular, has been extensively studied with regard to its role in HCV translation. PTB (57$\mathrm{kDa})$ is a member of the heterogeneous nuclear ribonucleoprotein (hnRNP) family and binds to pyrimidine-rich RNA sequences, which are present mostly in introns and untranslated regions of cellular and viral RNAs [10]. As an RNA-binding protein, PTB has four consensus RNA-recognition motifs (RRM). RRM 1 and 2, in the $\mathrm{N}$-terminal half of PTB, are required for PTB oligomerization and other protein-protein interactions, whereas RRM 3 and 4 , in the C-terminal half of PTB, are necessary for the RNA-binding activity [11]. PTB is involved in multiple steps of pre-mRNA processing, including tissue-specific splicing [12], mRNA localization [13, 14], regulation of polyadenylation [15], and transport of hepatitis B viral unspliced mRNA from nucleus to cytoplasm [16]. PTB localizes mainly in the nucleus and can shuttle between the nucleus and cytoplasm. Cytoplasmic PTB has been shown to either enhance or inhibit viral and cellular IRESdependent translation of RNA [17], depending on the type of IRES [18-20]. PTB has also been reported to bind to both the $\mathrm{HCV} 5^{\prime}$-untranslated region (UTR) [21] and $3^{\prime}$-UTR [22] and regulate $\mathrm{HCV}$ translation. In addition, PTB binds to a coreprotein-coding region of HCV RNA, which provides an additional mechanism for the regulation of HCV translation [23].

In this study, we further characterized the role of PTB in HCV replication. We showed that PTB is a component of HCV RNA replication complex and participates in viral RNA synthesis. Thus, PTB serves dual functions in HCV replication, including both translation and RNA replication. This observation also suggests an interesting relationship between translation and RNA replication in $\mathrm{HCV}$ life cycle.

\section{Materials and methods}

\section{Cells}

Huh-7 cells were grown at $37^{\circ} \mathrm{C}$ in Dulbecco's modified Eagle medium (DMEM) supplemented with $10 \%$ fetal bovine serum (FBS) and nonessential amino acids. Huh-7 cells harboring an $\mathrm{HCV}$ subgenomic replicon RNA derived from the HCV$\mathrm{N}$ strain [24, 25] were described previously [26].

\section{Antibodies}

The primary antibodies used for the analyses in this study included mouse anti-NS3 (Vector Laboratories, Burlingame, CA), anti-NS4B (ViroStat, Portland, ME), anti-NS5A (Biodesign, Saco, Maine, ME), anti-actin (Sigma, St. Louis, MO), anti-caveolin 2 (cav-2) (New England Biolads, Beverly, MA) monoclonal antibodies, a rat antihVAP-33 [27] and a rabbit anti-calnexin polyclonal antibody (Stressgen, Victoria, Canada). The mouse monoclonal antibody against NS5B was made by NS5B protein expressed from a recombinant baculovirus and was a generous gift of Dr. Soon Hwang (Hallym University, Korea) [28, 29]. The mouse monoclonal antibody against PTB isoforms 1, 2, and 4 (anti-PTB) was purified from culture medium of the mouse hybridoma cell, BB7, purchased from ATCC (Manassas, VA). The polyclonal antibody against the brain-specific PTB (anti-bPTB) was a generous gift of Dr. Douglas L. Black (UCLA).

\section{Labeling and immunofluorescene staining of de novo-synthesized viral RNA and PTB}

The procedures for cell permeabilization, labeling of de novo-synthesized viral RNA, immunofluorescence staining and confocal microscopy were modified from the previously described methods [30]. Briefly, Huh-7 or replicon cells were plated on 8 -well chamber slides at a density of $1 \times 10^{4}$ cells per well. Two days after seeding, cells were incubated with actinomycin D $(10 \mu \mathrm{g} / \mathrm{ml})$ for $1 \mathrm{~h}$ to inhibit cellular RNA synthesis. Subsequently, $2 \mathrm{mM}$ of bromouridine triphosphate (BrUTP) was tranfected into cells at $4{ }^{\circ} \mathrm{C}$ for $15 \mathrm{~min}$ using FuGENE 6 transfection reagent according to the manufacturer's instructions (Roche Molecular Biochemicals, Indianapolis, IN). The cells were washed with phosphate-buffered saline (PBS) twice and cultured at $37^{\circ} \mathrm{C}$ for $1 \mathrm{~h}$ with DMEM supplemented with $10 \%$ FBS. After incubation, cells were washed twice with PBS and subsequently fixed by $4 \%$ formaldehyde for $1 \mathrm{~h}$ at $4{ }^{\circ} \mathrm{C}$. For permeabilization, the cells were treated with $0.1 \%$ 
Triton X-100 (TX-100) (Sigma-Aldrich, St. Louis, MO) in PBS supplemented with 1\% FBS for 30 min at RT. Primary antibodies were diluted in PBS containing $1 \%$ bovine serum albumin (BSA) and incubated with cells for $1 \mathrm{~h}$ at RT. After three washes in PBS, the cells were incubated with fluorescein isothiocyanate (FITC)-conjugated or Rhodamine-conjugated secondary antibodies diluted at a 1:100 with PBS containing 5\% BSA for $1 \mathrm{~h}$ at RT. Then the cells were washed three times in PBS and mounted in Vectashield (Vector Laboratories, Burlingame, CA).

\section{Membrane flotation, detergent solubilization, and immunoblotting}

The membrane flotation assay was performed as previously described [31]. Briefly, Cells were first lysed in $1 \mathrm{ml}$ of hypotonic buffer $(10 \mathrm{mM}$ Tris$\mathrm{HCV}$ [pH 7.5], $10 \mathrm{mM} \mathrm{KCl}, 5 \mathrm{mM} \mathrm{MgCl}_{2}$ ) and passed through a 25 -gauge needle 20 times. Nuclei and unbroken cells were removed by centrifugation at $1,000 \times g$ for $5 \mathrm{~min}$ in microcentrifuge at $4{ }^{\circ} \mathrm{C}$. Cell lysates were then mixed with $3 \mathrm{ml}$ of $72 \%$ sucrose in low-salt buffer (LSB, comprising $50 \mathrm{mM}$ Tris- $\mathrm{HCl}$ [pH 7.5], $25 \mathrm{mM} \mathrm{KCl}$, and $5 \mathrm{mM} \mathrm{MgCl}_{2}$ ) and overlaid with $4 \mathrm{ml}$ of $55 \%$ sucrose in LSB, followed by $1.5 \mathrm{ml}$ of $10 \%$ sucrose in LSB. The sucrose gradient was centrifuged at $38,000 \mathrm{rpm}$ in a Beckman SW41 Ti rotor for $14 \mathrm{~h}$ for $4{ }^{\circ} \mathrm{C}$. After centrifugation, one-milliliter fractions were taken from the top of the gradient, and each was added $1.7 \mathrm{ml}$ of LSB to dilute sucrose and concentrated by being passed through a Centricon YM-30 or YM-100 filter unit (Millipore, Bedford, Mass.).

To characterize lipid rafts, postnuclear supernatants of cell lysates were incubated with $1 \%$ TX100 at 4 or $37^{\circ} \mathrm{C}$ for $1 \mathrm{~h}$ and followed by flotation centrifugation.

One half of each sucrose gradient fraction was separated by SDS-PAGE on $12 \%$ polyacrylamide gel and transferred to nitrocellulose membrane. After blocking of the membrane with PBS containing both $0.1 \%$ Tween 20 and 5\% Skim Milk, the membrane was incubated with the primary antibody for $1 \mathrm{~h}$ at $37^{\circ} \mathrm{C}$, followed by the appropriate species-specific horseradish peroxidase conjugate, for additional one hour at $37^{\circ} \mathrm{C}$. Bound antibody was detected by the ECL-plus system (Amersham, Piscataway, NJ).

\section{Proteinase digestion assay}

Proteinase digestion assay was performed as described previously [31]. Briefly, after the membrane flotation assay, the membrane fraction was treated without or with $1 \% \mathrm{TX}-100$ at 4 or $37{ }^{\circ} \mathrm{C}$ for $1 \mathrm{~h}$. Samples were then incubated with or without trypsin $(10,100 \mu \mathrm{g} / \mathrm{ml})$ at $4{ }^{\circ} \mathrm{C}$ for $5 \mathrm{~min}$. The reactions were stopped by adding $100 \mu \mathrm{g} / \mathrm{ml}$ of soybean trypsin inhibitor. Then samples were analyzed by immunoblotting.

\section{$R N A$ interference analysis}

The small interfering RNA (siRNA) of PTB targeting a 19-nt sequence corresponding to nt 1135-1153 of PTB open reading frame (ORF) [32] was chemically synthesized by Integrated DNA Technologies, Inc. (Coralville, Iowa). Nonspecific siRNA was purchased from Ambion (Austin, Tex). Huh-7 cells with or without a replicon were grown in DMEM containing 10\% FBS without antibiotics. For transfection, cells were plated at a density of $10^{5}$ cells per well in a 24 -well plate. Three $\mu \mathrm{l}$ of a $20 \mu \mathrm{M}$ stock of siRNA duplex was mixed with $47 \mu$ of Opti-MEM (Invitrogen, Carlsbad, Calif.) on day 2. In a separate tube, $3 \mu \mathrm{l}$ of Lipofectamine 2000 (Invitrogen) was mixed with $12 \mu \mathrm{l}$ of Opti-MEM, followed by incubation at RT for $7 \mathrm{~min}$. The two mixtures were combined and allowed to sit at RT for $25 \mathrm{~min}$. After incubation, $35 \mu \mathrm{l}$ of Opti-MEM was added and the $100 \mu \mathrm{l}$ mixture was directly added to the well containing $500 \mu \mathrm{l}$ of growth medium. On day 3 , cells were trypsinized and split into each of a 6-well plate. On day 4, cells were retransfected using $6 \mu \mathrm{l}$ of siRNA with $6 \mu \mathrm{l}$ of Lipofectamine 2000. On day 6, cells were harvested for either Western blot analysis or RNA isolation.

To determine the quantity of RNA by real-time PCR, we performed a single-tube reaction by using the TaqMan EZ RT-PCR Core Reagents (Applied Biosystems, Foster City, CA) as described previously [31]. Values were normalized to that of GAPDH (Applied Biosystems). Each test was done in triplicate and averages were obtained.

\section{Cell-Free replication assay and immunodepletion} experiment

Cell lysates of Huh-7 cells with or without an HCV replicon were prepared by a modified protocol 
from the published procedures [33]. Briefly, the cells grown in 100-mm-diameter dishes were washed with cold washing buffer $(150 \mathrm{mM}$ sucrose, $30 \mathrm{mM}$ HEPES [pH 7.4], $33 \mathrm{mM}$ ammonium chloride, $7 \mathrm{mM} \mathrm{KCl}, 4.5 \mathrm{mM}$ magnesium acetate), followed by treatment with lysolecithin buffer $(250 \mu \mathrm{g} / \mathrm{ml}$ of washing buffer $)$ for $2 \mathrm{~min}$. Three milliliters of washing buffer was added to each culture plate. The buffer was removed by aspiration. The cells were collected by scraping in $120 \mu \mathrm{l}$ of incomplete replication buffer $(100 \mathrm{mM}$ HEPES [pH 7.4]; $50 \mathrm{mM}$ ammonium chloride; $7 \mathrm{mM} \mathrm{KCl}$; $1 \mathrm{mM}$ spermidine; $1 \mathrm{mM}$ each of ATP, GTP, and UTP; $10 \mu \mathrm{M} \mathrm{CTP),} \mathrm{transferred} \mathrm{to}$ a new tube, and lysed gently by pipetting at least 15 times. The cell suspension was centrifuged at $1,600 \mathrm{rpm}$ in a microcentrifuge (Eppendorf) for 5 min at $4{ }^{\circ} \mathrm{C}$.

For immunodepletion experiment, a 40- $\mu$ l cytoplasmic fraction (supernatant) was treated with 1\% Nonidet P-40 (NP-40) (Boehringer Mannheim, Quebec, Canada) at $4{ }^{\circ} \mathrm{C}$ for $1 \mathrm{~h}$ and incubated with 0.1 or $1 \mu \mathrm{g}$ of antibody with an adjusted amount of PBS at $4{ }^{\circ} \mathrm{C}$ for $4 \mathrm{~h}$ with rotation. After incubation, the sample was further incubated with $\left[{ }^{32} \mathrm{P}\right] \mathrm{CTP}(30 \mu \mathrm{Ci} ; 800 \mathrm{Ci} / \mathrm{mmol})$, $10 \mu \mathrm{g}$ of actinomycin $\mathrm{D}$ per $\mathrm{ml}$ and $800 \mathrm{U}$ of RNase Inhibitor per ml (Promega Corporation, Madison, Wis.) for $3 \mathrm{~h}$ at $30^{\circ} \mathrm{C}$. Thereafter, RNA was extracted from the total mixture using the TRI Regent (Molecular Research Center, Inc., Cincinnati, OH). The RNA were precipitated and eluted in $10 \mu \mathrm{l}$ of RNase-free water. The RNA products were analyzed by formaldehyde-agarose $(1 \%)$ gel electrophoresis and autoradiography.

\section{Results}

Colocalization of cytoplasmic PTB with de novo-synthesized HCV RNA

Previous studies on the HCV replicon-harboring cells have shown that $\mathrm{HCV}$ replication occurs in the membrane-associated RCs [34]. Furthermore, the newly synthesized HCV RNA and the viral NS proteins colocalized on a distinct speckle-like structure, which is made of the detergent-resistant membranes (DRMs), in the cytoplasm of the replicon cells, [29]. To test the possibility that PTB not only participates in HCV translation, but also is associated with the HCV replication complex, we first determined the intracellular localization of PTB in the HCV replicon-containing cells. We performed immunofluorescence studies to localize PTB and the newly syntheisized HCV RNA by using short-term BrUTP labeling in the presence of actinomycin D. Double immunofluorescence staining using a polyclonal antibody against PTB and a monoclonal antibody against BrUTP showed that PTB was present almost exclusively in the nucleus, in agreement with the previous results [35]. In contrast, in the HCV replicon-containing cells, PTB was found not only in the nucleus, but also as distinct structures in the cytoplasm. The cytoplasmic PTB colocalized almost precisely with the BrUTP labels in the replicon cell (Figure 1). These results suggested that HCV RCs recruited PTB to distinct structures in the cytoplasm of the replicon cells.

\section{PTB localized in membrane fractions of replicon cells}

To determine the properties of the distinct structures that harbor cytoplasmic PTB, we performed membrane flotation experiments to separate membrane and cytosolic fractions of cell lysates. Cytoplasmic PTB in Huh-7 cells was detected mainly in the cytosol fractions; In contrast, PTB was detected in not only the cytosol fractions but also membrane fractions in replicon cells (Figure 2A), suggesting that PTB relocated from non-membrane fractions to membrane fractions in the cytoplasm of the cells containing $\mathrm{HCV}$ replicon. Interestingly, a smaller PTB fragment (S-PTB) was also detected in the cytosol fractions of the replicon cells. This small PTB fragment could also be detected in Huh-7 cells without $\mathrm{HCV}$ replicon, but only after very long exposure; furthermore, the relative ratio of S-PTB and the full-length PTB (F-PTB) was much higher in the replicon cells (Figure 2). These results suggest that $\mathrm{HCV}$ replicon induced the cleavage of PTB. Only the full-length PTB, but not S-PTB, was detected in the membrane fractions. The role of $\mathrm{S}$ PTB is still not clear.

\section{PTB was associated with a DRM structure containing $H C V N S$ proteins and $R N A$}

Previous studies have shown that HCV RCs were resistant to detergent treatment [8, 29, 31]. 


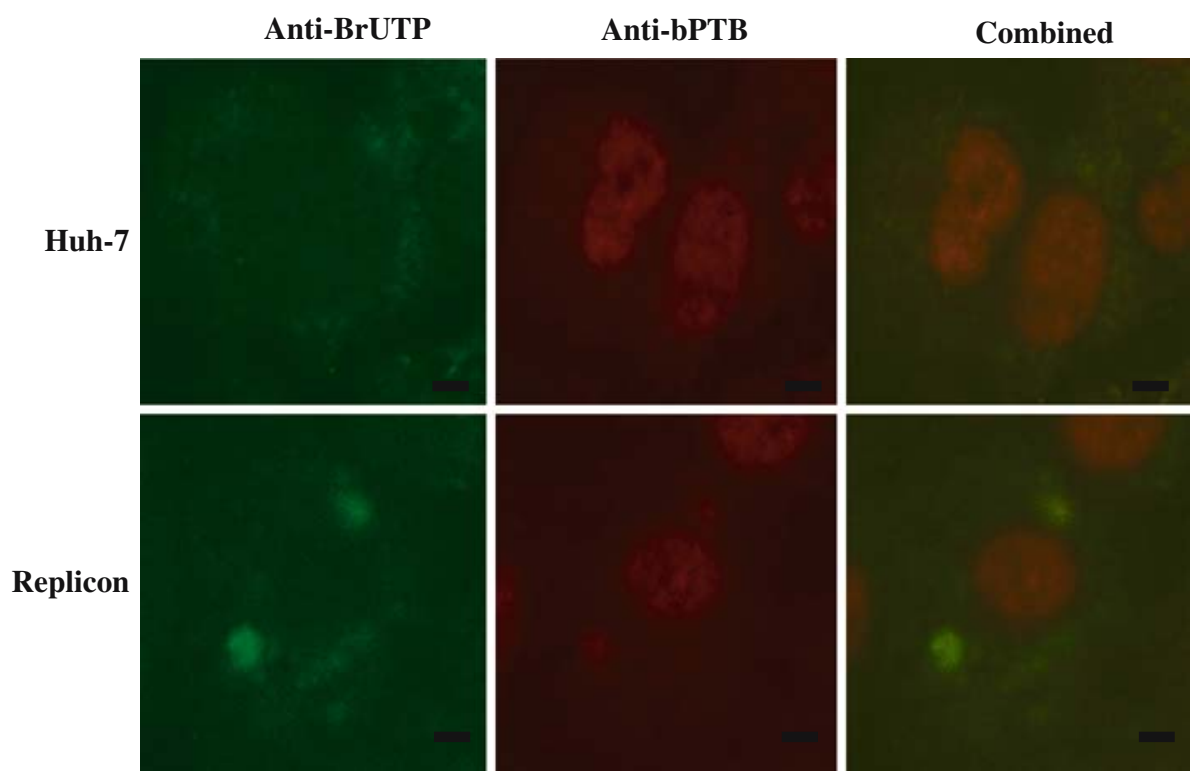

Figure 1. Colocalization of cytoplasmic PTB with de novo-synthesized HCV RNA. Two days after cell seeding, HCV replicon (Replicon) or control (Huh-7) cells were permeabilized and transfected with BrUTP for 15 min. They then were double stained with the mouse monoclonal antibody against BrdUTP (anti-BrUTP) and the rabbit polyclonal antibody against the brain-specific PTB (anti-bPTB). Bars, $5 \mu \mathrm{m}$.

Furthermore, cell-free HCV RNA replication activity was not affected by the detergent treatment $[31,36]$. To determine whether PTB was present in the HCV RC, we next studied whether PTB was present in the DRM structure. In this experiment, the lysates of the replicon cells after treatment with $1 \% \mathrm{TX}-100$ at $4{ }^{\circ} \mathrm{C}$ for $1 \mathrm{~h}$ were fractionated and concentrated by passing through a Centriplus YM-100 filter unit, which allows small proteins $(<100000 \mathrm{Da})$ to go through. Thus, only those proteins existing in large complexes could be detected. As shown in Figure 3, all the HCV nonstructural proteins studied, including NS3, NS4B, NS5A and NS5B, were found in the DRM fraction. hVAP-33, which is involved in the formation of HCV RC [8, 37], was also detected in the DRM. Significantly, PTB was detected in this membrane fraction in the replicon-containing cells, but not in Huh-7 cells. As shown previously, caveolin-2, a known DRM-resident protein was detected in the DRM fraction of both Huh-7 and replicon cells $(29,31$; see also Figure 4). These results indicated that $\mathrm{PTB}$, together with the $\mathrm{HCV}$ NS proteins and hVAP-33, was present as large complexes in the DRM fraction.
A

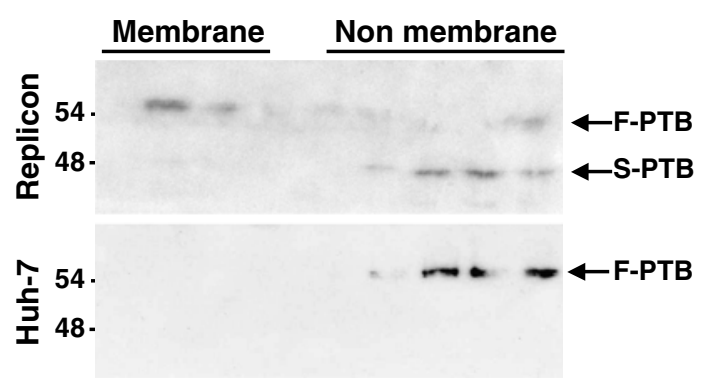

B

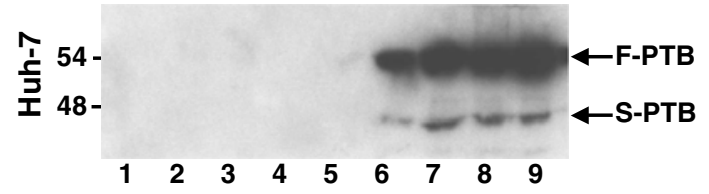

Figure 2. Detection of PTB in membrane fractions of HCV replicon cells. Cell lysates from HCV replicon (Replicon) or control (Huh-7) cells were fractionated by discontinuous sucrose gradient centrifugation. Each fraction was concentrated in a Centricon YM-30 filter unit and analyzed by SDS-PAGE on $12 \%$ polyacrylamide gel, followed by immunoblotting with antibodies against PTB (A). To detect the small PTB fragments, the membrane of Huh-7 cell lysates was exposed for 5 times longer (B). Fractions are numbered from 1 to 9 in order from top to bottom (light to heavy). The full-length PTB (F-PTB) and small PTB fragments (S-PTB) are indicated by arrows. 


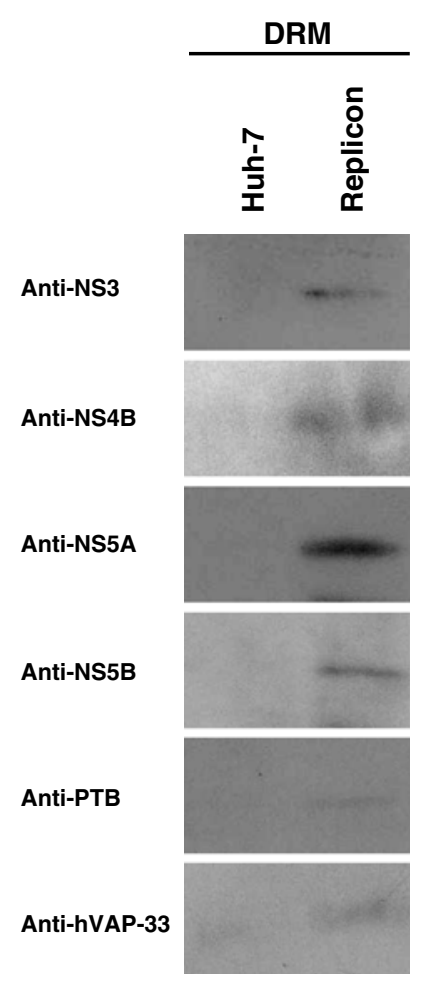

Figure 3. Detection of HCV proteins and PTB in DRM fractions of HCV replicon cells. Cell lysates from HCV replicon (Replicon) or control (Huh-7) cells were treated with 1\% TX100 for $60 \mathrm{~min}$ on ice and fractionated by discontinuous sucrose gradient centrifugation. DRM fraction was concentrated in a Centricon YM-100 filter unit and analyzed by SDS-PAGE, followed by immunoblotting with antibodies against NS3, NS4B, NS5A, NS5B, PTB or hVAP-33.

\section{Detergent solubilization of cytoplasmic PTB in $\mathrm{HCV}$ replicon cells}

To further establish that PTB is associated with lipid rafts, the detergent solubility of PTB under different conditions was studied. Cell lysates of replicon cells were treated with $1 \%$ TX-100 at either 4 or $37^{\circ} \mathrm{C}$ before equilibrium flotation centrifugation. The results showed that both PTB and cav-2, a lipid raft marker [38], were recovered in the membrane-containing fractions after the TX-100 treatment at $4{ }^{\circ} \mathrm{C}$. In contrast, the ER protein calnexin was solubilized by $\mathrm{TX}-100$ at $4{ }^{\circ} \mathrm{C}$ (Figure 4). After treatment with TX-100 at $37^{\circ} \mathrm{C}$, the association of PTB or cav-2 with DRM structure was disrupted, as was observed for other raft-resident proteins [39]. HCV NS proteins were also shifted to the detergent-soluble fractions after treatment with TX-100 at $37{ }^{\circ} \mathrm{C}$ [31]. These results are consistent with the interpretation that the DRM structures containing PTB are lipid rafts.

$P T B$ in the membrane fraction was resistant to protease digestion, but became sensitive after treatment with the raft-disrupting agents

Previous studies have shown that HCV RCs were protected within the membrane structure associated with lipid rafts [31]. We therefore examined whether PTB was also enclosed within lipid rafts. We determined trypsin sensitivity of PTB in the DRM fractions. As shown in Figure 5, in the absence of detergent treatment, most of PTB was resistant to trypsin digestion even at a very high concentration of trypsin $(100 \mu \mathrm{g} / \mathrm{ml})$. After the membrane was treated with $1 \%$ TX-100 at $4{ }^{\circ} \mathrm{C}$, at least some PTB was not digested. In contrast, after treatment with $1 \%$ TX-100 at $37{ }^{\circ} \mathrm{C}$, PTB was completely digested by trypsin $(100 \mu \mathrm{g} / \mathrm{ml})$. This result suggested that at least part of PTB in DRM is protected by lipid raft. Alternatively, all of PTB are in lipid rafts, but the protection may not be complete.

\section{PTB in DRM fraction of replicon cells consists of multiple isoforms and a paralog}

Several isoforms and paralogs of PTB have been reported [10, 40, 41]. Brain-specific PTB is known to be a different gene product of PTB, i.e., a paralog of PTB. To determine whether there was differential incorporation of PTB components into the HCV RC, we performed immunoblotting by using different antibodies, including a monoclonal antibody that can detect PTB isoforms 1, 2, and 4 (anti-PTB) and a mouse polyclonal antibody specific for the brain-specific PTB (anti-bPTB) [42]. The anti-bPTB antibody detected a PTB species in the cytosol of mouse brain but not mouse kidney (Figure 6A left panel), whereas the anti-PTB antibody detected PTB isoform 1 in the kidney and a very faint band corresponding to PTB isoforms 2 and 4 in the brain (Figure 6A, right panel). Since bPTB and PTB isoforms 2 and 4 have very similar sizes, we could not distinguish the possibilities that the anti-PTB antibody crossreacted with $\mathrm{bPTB}$ or that $\mathrm{PTB}$ isoforms 2 and 4 were also present in the brain. Huh-7 cells contained both PTB isoforms 2 and 4 and bPTB (Figure 6A). Interestingly, PTB was also detected 


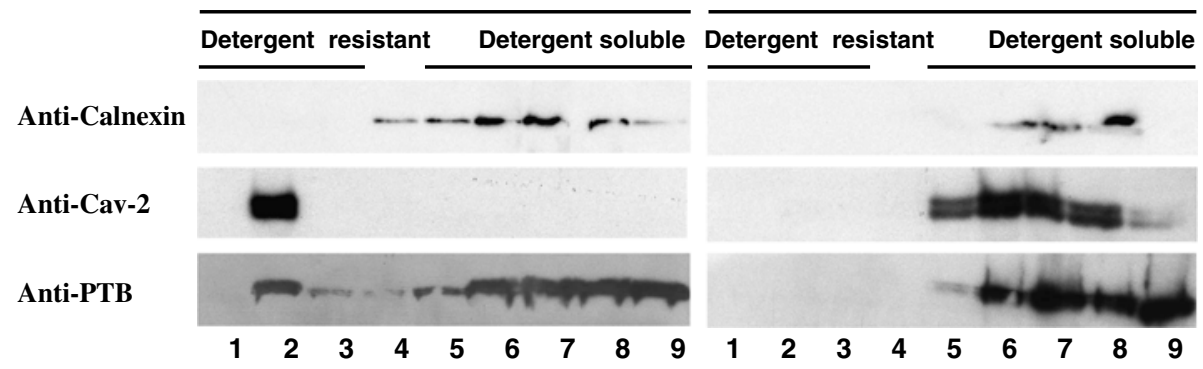

Figure 4. Detergent solublization of PTB in HCV replicon cells. Cell lysates of replicon cells were either treated with $1 \%$ TX-100 at 4 or $37^{\circ} \mathrm{C}$, and fractionated by discontinuous sucrose gradient centrifugation. Each fraction was concentrated in a Centricon YM-30 filter unit. Equal volumes of the recovered fractions were analyzed by SDS-PAGE, followed by immunoblotting with antibodies against PTB, calnexin (ER marker), or cav-2 (lipid raft marker). Fractions are numbered from 1 to 9 in order from top to bottom (light to heavy).

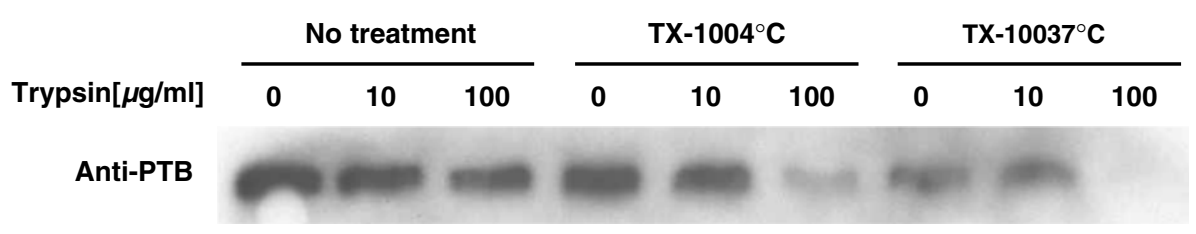

Figure 5. Protease sensitivity of PTB in the HCV RC. Cell lysates of replicon cells were fractionated by flotation sucrose gradient centrifugation. Fraction 2, which contains membrane, was concentrated in a Centriplus YM-30 filter unit and incubated without or with $1 \%$ TX-100 at 4 or $37{ }^{\circ} \mathrm{C}$ for $1 \mathrm{~h}$. Then the samples were incubated without or with either 10 or $100 \mu \mathrm{g} / \mathrm{ml}$ of trypsin for 5 min on ice. The digestion was terminated by adding Soybean trypsin inhibitor and analyzed by SDS-PAGE and immunoblotted with the monoclonal antibody against PTB.

in the DRM fraction of the mouse brain and kidney (Figure 6B); the physiological significance of this finding is currently unknown. In Huh-7 cells containing the HCV replicon, bPTB and PTB isoforms 2 and 4 were also detected in the DRM fraction, This result suggested that all the PTB species in Huh-7 cells were incorporated into the HCV RC.

\section{In vivo knockdown of PTB inhibited $\mathrm{HCV}$} replication

To further examine the role of PTB in HCV replication in vivo, we attempted to knock down the endogenous PTB expression using the RNA interference method [32]. Replicon cells were transfected with either PTB-specific or nonspecific siRNA. The PTB siRNA caused a significant reduction of the endogenous PTB (Figure 7A). Correspondingly, PTB siRNA caused a reduction of HCV RNA to a level around $40-50 \%$ that of the cells treated with the nonspecific siRNA (Figure 7B). These results concluded that PTB was a positive regulator of HCV RNA synthesis.

\section{Depletion of PTB from cellular lysates inhibited $H C V R N A$ replication in vitro}

The finding that the reduction of endogenous PTB inhibited viral RNA synthesis could be due to the possibilities that PTB is directly involved in both viral transcription and translation or that the inhibition of RNA replication was the indirect result of inhibition of viral protein synthesis. To distinguish these possibilities, we designed experiments to separate viral transcription from viral translation. We performed an in vitro replication assay using HCV RCs in crude membrane fractions of the replicon cells [31, 33, 43, 44]. Furthermore, we performed immunodepletion of PTB from the lysates to assess the effects of PTB in RNA replication in vitro. Cell lysates of replicon cells or Huh-7 cells were treated with detergent $\left(\mathrm{NP}-40\right.$ at $\left.4{ }^{\circ} \mathrm{C}\right)$ and incubated with antibodies against PTB, HCV NS4B, or HCV E2 proteins. After incubation, HCV RNA replication under the cell-free condition was carried out. Both anti-PTB and anti-NS4B antibodies inhibited HCV RNA synthesis in a dose-dependent manner (Figure 8). 

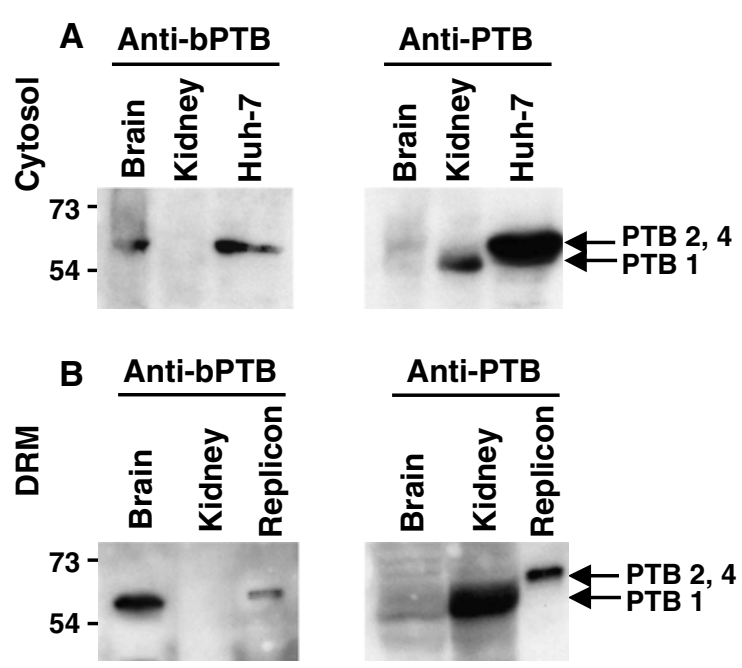

Figure 6. Isoforms and paralogs of PTB in HCV replicon cells. PTB in cytosol (A) or DRM fraction (B) of the HCV replicon cell lysates (Replicon) was separated by SDS-PAGE and immunoblotted with monoclonal antibody against PTB 1, 2, 4 (anti-PTB) or brain-specific PTB (anti-bPTB). Brain and Kidney tissues were used for controls of brain-specific PTB and isoform 1 PTB, respectively. PTB 1,2 , and 4 are indicated by arrows.

This result is consistent with the interpretation that PTB and NS4B are components of HCV RCs and are required for RNA synthesis. In contrast,
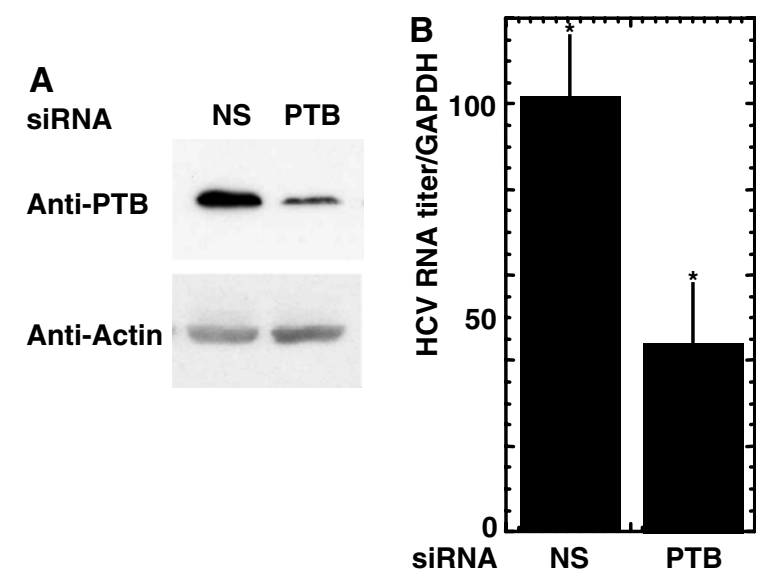

Figure 7. Inhibition of viral RNA replication by siRNA against PTB. HCV replicon cells were treated with PTBspecific or nonspecific (NS) siRNA twice and harvested at $48 \mathrm{~h}$ after the second siRNA transfection and analyzed for PTB expression by immunoblotting with PTB antibody (A) and for HCV RNA titer by real-time quantitative RT-PCR (B). GAPDH mRNA was used as the internal control. The relative RNA titer in the PTB siRNA-treated cells was compared with that treated with the nonspecific siRNA. Error bars denote standard deviations with asterisks indicating statistical significance $\left({ }^{*} p<0.05\right)$.
anti-E2 antibody did not significantly affect $\mathrm{HCV}$ RNA synthesis at $0.1,1.0 \mu \mathrm{g} / \mathrm{ml}$ (Figure 8 ) or even $10 \mu \mathrm{g} / \mathrm{ml}$ of antibody concentrations tested (data not shown). This result is expected since E2 protein is not a component of HCV RCs. These combined results provided direct evidence that PTB is a part of the HCV RNA replication complex and participates directly in viral RNA synthesis.

\section{Discussion}

The use of BrUTP labeling has enabled us to characterize active HCV RNA replication in situ. Previously, we have shown that HCV RNA replication occurs on speckle-like structures [29], which may be equivalent to the membranous web, as reported by Gosert et al. [45]. The immunofluorescence staining study presented here showed that PTB in Huh-7 cells mainly existed in the nucleus, while PTB in the replicon cells localized in not only the nucleus but also distinct structures in the cytoplasm and colocalized with the newly synthesized HCV RNA (Figure 1). These results suggest strongly that $\mathrm{PTB}$ is recruited into the $\mathrm{HCV}$ replication complex. PTB is thought to be a nuclear protein in the static state. It can shuttle between the nucleus and cytoplasm, because the RRM 2 domain of PTB facilitates the nuclear export of PTB, whereas RRM 1, 3, and 4 may contribute to the nuclear localization of PTB [4648]. PTB is also an RNA-binding protein; indeed, PTB has been shown to bind to both $5^{\prime}$ UTR [21]

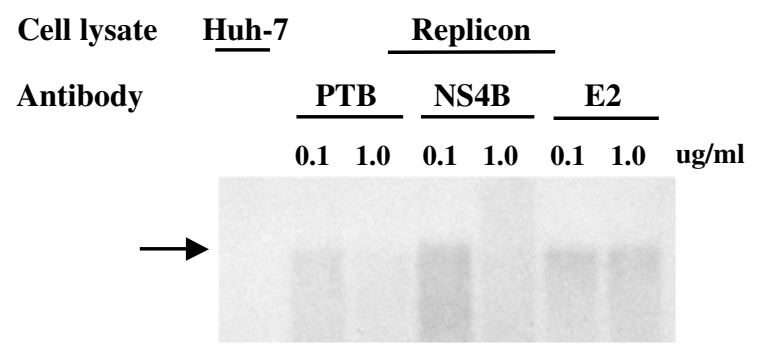

Figure 8. Inhibition of cell-free replication activity by antiPTB antibody. Cell lysates from HCV replicon (Replicon) or control (Huh-7) cells were incubated without or with monoclonal antibodies against PTB, HCV E2, or NS4B at two different concentrations $(0.1$ and $1 \mathrm{ug} / \mathrm{ml})$. Samples were incubated with $\left[\alpha^{32} \mathrm{P}\right] \mathrm{CTP}$ in the cell-free replication assay. The RNA products were analyzed by formaldehyde-agarose gel electrophoresis. 
and $3^{\prime} \mathrm{UTR}$ of HCV RNA [23]. This binding conceivably facilitates the recruitment of PTB to the HCV RC. One notable feature of cellular factors involved in viral RNA synthesis is that they are located predominantly in the nucleus of normal cells, while viral RNA synthesis occurs mostly in the cytoplasm [4]. However, the relocalization of cellular proteins from nucleus to cytoplasm in virus-infected cells has previously been demonstrated for several proteins, including $\mathrm{La}$, hnRNP A1, and PTB [49-51]. Here we also showed the relocalization of PTB from nucleus to cytoplasm in HCV replicon cells. Thus, this is likely a common feature of RNA viruses.

Membrane flotation experiments showed that a significant fraction of the full-length PTB shifted from cytosol to membranes in the cytoplasm of $\mathrm{HCV}$ replicon cells (Figure 2A). On the other hand, the majority of a small PTB cleavage fragment remained in the cytosolic fractions. These results suggested that only the full-length PTB could be recruited to membrane fraction and participate in HCV replication. The mechanism of generation and function of the small PTB fragment is not clear. It has been reported that PTB is cleaved by caspase-3 during apoptosis [52] or by poliovirus $3 \mathrm{C}^{\text {pro }}$ and/or $3 \mathrm{CD}^{\text {pro }}$ [53]; the Cterminal PTB fragment was localized to the cytoplasm. Interestingly, the small PTB fragments have been shown to inhibit polioviral IRESdependent translation, suggesting that the cleavage of PTBs may contribute to the molecular switching from translation to replication of poliovirus RNA. Moreover, modulation of translation by proteolytic cleavage of a translation initiation factor eIF4GII is a mechanism for shutting down the host cell protein synthesis by poliovirus [54]. The small PTB fragments present in mouse tissues have been reported to prevent PTB binding to $5^{\prime} \mathrm{UTR}$ and inhibit IRES-dependent translation of hepatitis A virus [55]. Thus, the small PTB fragments found in $\mathrm{HCV}$ replicon cells may similarly contribute to the molecular switching from translation to replication, or vice versa, of HCV RNA.

In this study, we demonstrated that the DRM structure from the replicon cells contained not only HCV NS proteins but also PTB and hVAP-33 (Figure 3). Recently, we have demonstrated by membrane flotation analysis that HCV RNA and NS proteins of replicon cells are present mainly in DRM fractions [29, 31]. Cell-free, de novo HCV replication assay further showed that HCV RNA and NS proteins in DRM fractions could carry out RNA replication in vitro [31]. Waris et al. [36] also found purified RCs to be resistant to an even higher concentration of NP-40. These results together support the notion that the active $\mathrm{HCV}$ RCs existed in DRM structure that consists of lipid rafts. On the other hand, Lai et al. [44] showed that the RNA replication activity of $\mathrm{HCV}$ $\mathrm{RC}$ was inhibited by a lower concentration of NP40. The difference in the detergent sensitivity of HCV RNA replication between our studies and the other report may be attributed to the proportion of NS proteins existing in DRM fraction. Indeed, the proportion of total NS5B protein present in the DRM fraction was variable in different replicon cell lines (data not shown). Furthermore, HCV RNA titers in different replicon cell lines appear to correlate with the amount of NS5B in the DRM fraction (data not shown).

In this study, PTB in the DRM was shown to be resistant to protease digestion, but become sensitive after treatment of DRM with the raftdisrupting agents. This result was similar to the results of RNase and protease treatments of $\mathrm{HCV}$ RNA and NS proteins in the DRM of replicon cells, respectively [31]. These results together indicated that HCV RNA, NS proteins, and PTB in $\mathrm{HCV}$ RCs were protected within membrane structure associated with lipid rafts. We detected in HCV RC several isoforms and a paralog of PTB, including PTB 2, 4, and brain-specific PTB in Huh-7 cells. A previous study has shown that several members of heterogeneous nuclear ribonucleoprotein (hnRNP) type A/B family, including hnRNP A1, hnRNP A/B, hnRNP A2/B1, and hnRNP A3, interacted with mouse hepatitis virus RNA and function interchangeably in the replication of viral RNA [56]. Similarly, all of the isoforms and paralog of PTB may be functional in HCV RNA replication as well.

We showed that the reduction of PTB expression level in replicon cells inhibited HCV RNA replication (Figure 7). Previously, Zhang et al. [57] also obtained the similar results by using siRNA targeting several cellular proteins, including PTB, hVAP-33 and La antigen. In this report, we have further demonstrated that PTB is directly involved in viral transcription by demonstrating that immunodepletion of PTB from the lysates inhibited RNA replication in a cell-free 
HCV RNA replication assay. Therefore, PTB is a component of $\mathrm{HCV}$ RCs and necessary for HCV RNA synthesis. Our studies presented here thus confirmed and extended the recent publications on the roles of PTB in HCV RNA replication [58, 59]. However, we do not know exactly how the PTB antibodies interfered with RNA replication in the cell lysates. They could simply prevent PTB from being incorporated into the HCV RCs, or they could interfere with its function after assembly of the HCV RCs. Lai et al. [44] demonstrated that HCV RC preparation could not use exogenous RNA as template and that the newly synthesized single-strand RNA could serve as the template for an additional round of RNA synthesis. HCV proteins have been shown to be relatively stable [60]. Shi et al. [29] suggested that HCV RNA replication did not rely on continuous protein synthesis. The NS proteins and HCV RNA in RCs are thus capable of multiple rounds of RNA synthesis. These data are consistent with our observation that the HCV RCs were made up of the lipid- raft-containing membranes, so that exogenous RNA, RNase, and protease could not access the internal components of RCs. We propose several possible mechanisms for the involvement of PTB in HCV RNA translation and replication. First, PTB may bind to both the $5^{\prime}$ and $3^{\prime}$ ends of HCV RNA [21, 22], potentially allowing the $5^{\prime}$ and $3^{\prime}$-end interactions through a single protein. The $5^{\prime}-3^{\prime}$ crosstalk of RNA may cause circularization of viral genome, which may help both RNA replication and translation. The 5 '- and 3'-end interactions are important for RNA synthesis of many RNA viruses [61, 62]. Second, PTB may be involved in the formation of $\mathrm{HCV}$ RCs; for example, PTB may recruit HCV RNA into the RCs by interacting with both HCV RNA and NS proteins or other components (e.g., hVAP-33) of RCs. Third, PTB may change the conformation of viral RNA into one that is more favorable for replication and translation, probably functioning as an RNA chaperon to unfold the highly structured untranslated region of $\mathrm{HCV}$ RNA.

Our studies here showed that PTB is involved in HCV RNA replication. Previously, our laboratory and others have shown that PTB regulates HCV translation [21, 22]. These findings support the potential linkage between viral RC and the translation machinery. PTB may be one of the key factors involved in the transition of viral RNA from HCV RCs to the HCV translation machineries. The small PTB fragments may be induced by $\mathrm{HCV}$ replicon and play a role in the switch from translation to replication or vice versa. Whether other components of the HCV RCs are important for both replication and translation will be interesting issues for future studies.

\section{Acknowledgments}

We acknowledge microscope analysis provided by the microscopy sub core at the USC Center for Liver Diseases. This work was supported by NIH grants awarded to MMCL.

\section{References}

1. Choo Q.L., Kuo G., Weiner A.J., Overby L.R., Bradley D.W. and Houghton M., Isolation of a cDNA clone derived from a blood-borne non-A, non-B viral hepatitis genome. Science 244: 359-362, 1989.

2. Kuo G., Choo Q.L., Alter H.J., Gitnick G.L., Redeker A.G., Purcell R.H., Miyamura T., Dienstag J.L., Alter M.J., Stevens C.E. et al, An assay for circulating antibodies to a major etiologic virus of human non- $A$, non- $B$ hepatitis. Science 244: 362-364, 1989.

3. Saito I., Miyamura T., Ohbayashi A., Harada H., Katayama T., Kikuchi S., Watanabe Y., Koi S., Onji M., Ohta Y. et al, Hepatitis $C$ virus infection is associated with the development of hepatocellular carcinoma. Proc. Natl. Acad. Sci. USA 87: 6547-6549, 1990.

4. Lai M.M., Cellular factors in the transcription and replication of viral RNA genomes: a parallel to DNAdependent RNA transcription. Virology 244: 1-12, 1998.

5. Ito T. and Lai M.M., An internal polypyrimidine-tractbinding protein-binding site in the hepatitis $\mathrm{C}$ virus RNA attenuates translation, which is relieved by the $3^{\prime}$ untranslated sequence. Virology 254: 288-296, 1999.

6. Ali N., Pruijn G.J., Kenan D.J., Keene J.D. and Siddiqui A., Human La antigen is required for the hepatitis $\mathrm{C}$ virus internal ribosome entry site-mediated translation. J. Biol. Chem. 275: 27531-27540, 2000.

7. Kim J.H., Paek K.Y., Ha S.H., Cho S., Choi K., Kim C.S., Ryu S.H. and Jang S.K., A cellular RNA-binding protein enhances internal ribosomal entry site-dependent translation through an interaction downstream of the hepatitis $\mathrm{C}$ virus polyprotein initiation codon. Mol. Cell Biol. 24: 7878-7890, 2004

8. Gao L., Aizaki H., He J.W. and Lai M.M., Interactions between viral nonstructural proteins and host protein hVAP33 mediate the formation of hepatitis $\mathrm{C}$ virus RNA replication complex on lipid raft. J. Virol. 78: 3480-3488, 2004.

9. Hamamoto I., Nishimura Y., Okamoto T., Aizaki H., Liu M., Mori Y., Abe T., Suzuki T., Lai M.M., Miyamura T., Moriishi K. and Matsuura Y., Human VAP-B is involved in hepatitis $\mathrm{C}$ virus replication through interaction with NS5A and NS5B. J. Virol. 79: 13473-13482, 2005. 
10. Ghetti A., Pinol-Roma S., Michael W.M., Morandi C. and Dreyfuss G., hnRNP I, the polypyrimidine tract-binding protein: distinct nuclear localization and association with hnRNAs. Nucleic Acids Res. 20: 3671-3678, 1992.

11. Oh Y.L., Hahm B., Kim Y.K., Lee H.K., Lee J.W., Song O., Tsukiyama-Kohara K., Kohara M., Nomoto A. and Jang S.K., Determination of functional domains in polypyrimidine-tract-binding protein. Biochem. J. 331: 169-175, 1998.

12. Wagner E.J. and Garcia-Blanco M.A., Polypyrimidine tract binding protein antagonizes exon definition. Mol. Cell Biol. 21: 3281-3288, 2001.

13. Cote C.A., Gautreau D., Denegre J.M., Kress T.L., Terry N.A. and Mowry K.L., A Xenopus protein related to hnRNP I has a role in cytoplasmic RNA localization. Mol. Cell 4: 431-437, 1999.

14. Schnapp B.J., A glimpse of the machinery. Curr. Biol. 7: R725-R727, 1999.

15. Moreira A., Takagaki Y., Brackenridge S., Wollerton M., Manley J.L. and Proudfoot N.J., The upstream sequence element of the $\mathrm{C} 2$ complement poly(A) signal activates mRNA $3^{\prime}$ end formation by two distinct mechanisms. Genes Dev. 15: 2522-2534, 1998.

16. Zang W.Q., Li B., Huang P.Y., Lai M.M. and Yen T.S. Role of polypyrimidine tract binding protein in the function of the hepatitis B virus posttranscriptional regulatory element. J. Virol. 75: 10779-10786, 2001.

17. Belsham G.J. and Sonenberg N., RNA-protein interactions in regulation of picornavirus RNA translation. Microbiol. Rev. 60: 499-511, 1996.

18. Hellen C.U., Witherell G.W., Schmid M., Shin S.H., Pestova T.V., Gil A. and Wimmer E., A cytoplasmic 57$\mathrm{kDa}$ protein that is required for translation of picornavirus RNA by internal ribosomal entry is identical to the nuclear pyrimidine tract-binding protein. Proc. Natl. Acad. Sci. USA 90: 7642-7646, 1993.

19. Kaminski A., Hunt S.L., Patton J.G. and Jackson R.J., Direct evidence that polypyrimidine tract binding protein (PTB) is essential for internal initiation of translation of encephalomyocarditis virus RNA. RNA 1: 924-938, 1995.

20. Kim Y.K., Hahm B. and Jang S.K., Polypyrimidine tractbinding protein inhibits translation of bip mRNA. J. Mol. Biol. 304: 119-33, 2000.

21. Ali N. and Siddiqui A., Interaction of polypyrimidine tractbinding protein with the $5^{\prime}$ noncoding region of the hepatitis $\mathrm{C}$ virus RNA genome and its functional requirement in internal initiation of translation. J. Virol. 69: 6367$6375,1995$.

22. Ito T. and Lai M.M., Determination of the secondary structure of and cellular protein binding to the $3^{\prime}$-untranslated region of the hepatitis $\mathrm{C}$ virus RNA genome. J. Virol. 71: 8698-8706, 1997.

23. Ito T., Tahara S.M. and Lai M.M., The 3'-untranslated region of hepatitis $\mathrm{C}$ virus RNA enhances translation from an internal ribosomal entry site. J. Virol. 72: 8789-8796, 1998.

24. Guo J.T., Bichko V.V. and Seeger C., Effect of alpha interferon on the hepatitis $\mathrm{C}$ virus replicon. J. Virol. 75 : 8516-8523, 2001.

25. Ikeda M., Yi M., Li K. and Lemon S.M., Selectable subgenomic and genome-length dicistronic RNAs derived from an infectious molecular clone of the HCV-N strain of hepatitis $\mathrm{C}$ virus replicate efficiently in cultured Huh7 cells. J. Virol. 76: 2997-3006, 2002.
26. Lee K.J., Choi J., Ou J.H. and Lai M.M., The C-terminal transmembrane domain of hepatitis $\mathrm{C}$ virus (HCV) RNA polymerase is essential for $\mathrm{HCV}$ replication in vivo. J. Virol. 78: 3797-3802, 2004.

27. Tu H., Gao L., Shi S.T., Taylor D.R., Yang T., Mircheff A.K., Wen Y., Gorbalenya A.E., Hwang S.B. and Lai M.M., Hepatitis C virus RNA polymerase and NS5A complex with a SNARE-like protein. Virology 263: 30-41, 1999.

28. Hwang S.B., Park K.J., Kim Y.S., Sung Y.C. and Lai M.M., Hepatitis C virus NS5B protein is a membraneassociated phosphoprotein with a predominantly perinuclear localization. Virology 227: 439-446, 1997.

29. Shi S.T., Lee K.J., Aizaki H., Hwang S.B. and Lai M.M., Hepatitis $\mathrm{C}$ virus RNA replication occurs on a detergentresistant membrane that cofractionates with caveolin-2. J. Virol. 77: 4160-4168, 2003.

30. Kanestrom A., Andresen V., Szilvay A.M., Kalland K.H and Haukenes G., Histographic recording of human immunodeficiency virus type 1 (HIV-1) regulatory protein Rev and nuclear factors. Arch. Virol. 143: 279-294, 1998.

31. Aizaki H., Lee K.J., Sung V.M., Ishiko H. and Lai M.M., Characterization of the hepatitis C virus RNA replication complex associated with lipid rafts. Virology 324: 450-461, 2004

32. Wagner E.J. and Garcia-Blanco M.A., RNAi-mediated PTB depletion leads to enhanced exon definition. Mol. Cell. 10: 943-949, 2002.

33. Ali N., Tardif K.D. and Siddiqui A., Cell-free replication of the hepatitis $\mathrm{C}$ virus subgenomic replicon. J. Virol. 76: 12001-12007, 2002.

34. Bartenschlager R. and Lohmann V., Replication of hepatitis C virus. J. Gen. Virol. 81: 1631-1648, 2000.

35. Huang S., Deerinck T.J., Ellisman M.H. and Spector D.L., The dynamic organization of the perinucleolar compartment in the cell nucleus. J. Cell Biol. 137: 965-974, 1997.

36. Waris G., Sarker S. and Siddiqui A., Two-step affinity purification of the hepatitis $\mathrm{C}$ virus ribonucleoprotein complex. RNA 10: 321-329, 2004

37. Evans M.J., Rice C.M. and Goff S.P., Phosphorylation of hepatitis $\mathrm{C}$ virus nonstructural protein $5 \mathrm{~A}$ modulates its protein interactions and viral RNA replication. Proc. Natl. Acad. Sci. USA 101: 13038-13043, 2004.

38. Smart E.J., Graf G.A., McNiven M.A., Sessa W.C., Engelman J.A., Scherer P.E., Okamoto T. and Lisanti M.P., Caveolins, liquid-ordered domains, and signal transduction. Mol. Cell Biol. 19: 7289-7304, 1999.

39. Brown D.A. and Rose J.K., Sorting of GPI-anchored proteins to glycolipid-enriched membrane subdomains during transport to the apical cell surface. Cell 68: 533544, 1992

40. Gil A., Sharp P.A., Jamison S.F. and Garcia-Blanco M.A., Characterization of cDNAs encoding the polypyrimidine tract-binding protein. Genes Dev. 5: 1224-1236, 1991.

41. Patton J.G., Mayer S.A., Tempst P. and Nadal-Ginard B., Characterization and molecular cloning of polypyrimidine tract-binding protein: a component of a complex necessary for pre-mRNA splicing. Genes Dev. 5: 1237-1251, 1991.

42. Chan R.C. and Black D.L., The polypyrimidine tract binding protein binds upstream of neural cell-specific c-src exon N1 to repress the splicing of the intron downstream. Mol. Cell Biol. 17: 4667-4676, 1997.

43. Hardy R.W., Marcotrigiano J., Blight K.J., Majors J.E. and Rice C.M., Hepatitis C virus RNA synthesis in a 
cell-free system isolated from replicon-containing hepatoma cells. J. Virol. 77: 2029-2037, 2003.

44. Lai V.C., Dempsey S., Lau J.Y., Hong Z. and Zhong W., In vitro RNA replication directed by replicase complexes isolated from the subgenomic replicon cells of hepatitis $\mathrm{C}$ virus. J. Virol. 77: 2295-2300, 2003.

45. Gosert R., Egger D., Lohmann V., Bartenschlager R., Blum H.E., Bienz K. and Moradpour D., Identification of the hepatitis $\mathrm{C}$ virus RNA replication complex in huh-7 cells harboring subgenomic replicons. J. Virol. 77: 54875492, 2003.

46. Li B. and Yen T.S., Characterization of the nuclear export signal of polypyrimidine tract-binding protein. J. Biol. Chem. 277: 10306-10314, 2002.

47. Perez I., McAfee J.G. and Patton J.G., Multiple RRMs contribute to RNA binding specificity and affinity for polypyrimidine tract binding protein. Biochemistry 36 : 11881-11890, 1997.

48. Kamath R.V., Leary D.J. and Huang S., Nucleocytoplasmic shuttling of polypyrimidine tract-binding protein is uncoupled from RNA export. Mol. Biol. Cell 12: 38083820, 2001.

49. Li H.P., Zhang X., Duncan R., Comai L. and Lai M.M., Heterogeneous nuclear ribonucleoprotein Al binds to the transcription-regulatory region of mouse hepatitis virus RNA. Proc. Natl. Acad. Sci. USA 94: 9544-9549, 1997.

50. McBride A.E., Schlegel A. and Kirkegaard K., Human protein Sam68 relocalization and interaction with poliovirus RNA polymerase in infected cells. Proc. Natl. Acad. Sci. USA 93: 2296-2301, 1996

51. Meerovitch K., Svitkin Y.V., Lee H.S., Lejbkowicz F., Kenan D.J., Chan E.K., Agol V.I., Keene J.D. and Sonenberg N., La autoantigen enhances and corrects aberrant translation of poliovirus RNA in reticulocyte lysate. J. Virol. 67: 3798-3807, 1993.

52. Back S.H., Shin S. and Jang S.K., Polypyrimidine tractbinding proteins are cleaved by caspase-3 during apoptosis. J. Biol. Chem. 277: 27200-27209, 2002.

53. Back S.H., Kim Y.K., Kim W.J., Cho S., Oh H.R., Kim J.E. and Jang S.K., Translation of polioviral mRNA is inhibited by cleavage of polypyrimidine tract-binding proteins executed by polioviral 3C(pro). J. Virol. 76: 2529-2542, 2002.

54. Gradi A., Svitkin Y.V., Imataka H. and Sonenberg N., Proteolysis of human eukaryotic translation initiation factor eIF4GII, but not eIF4GI, coincides with the shutoff of host protein synthesis after poliovirus infection. Proc. Natl. Acad. Sci. USA 95: 11089-11094, 1998.

55. Venkatramana M., Ray P.S., Chadda A. and Das S., A $25 \mathrm{kDa}$ cleavage product of polypyrimidine tract binding protein (PTB) present in mouse tissues prevents PTB binding to the $5^{\prime}$ untranslated region and inhibits translation of hepatitis A virus RNA. Virus Res. 98: 141-149, 2003.

56. Shi S.T., Yu G.Y. and Lai M.M., Multiple type A/B heterogeneous nuclear ribonucleoproteins (hnRNPs) can replace hnRNP A1 in mouse hepatitis virus RNA synthesis. J. Virol. 77: 10584-10593, 2003.

57. Zhang J., Yamada O., Sakamoto T., Yoshida H., Iwai T., Matsushita Y., Shimamura H., Araki H. and Shimotohno K., Down-regulation of viral replication by adenoviralmediated expression of siRNA against cellular cofactors for hepatitis C virus. Virology 320: 135-143, 2004.

58. Chang K.S. and Luo G., The polypyrimidine tract-binding protein (PTB) is required for efficient replication of hepatitis C virus (HCV) RNA. Virus Res. 115: 1-8, 2006.

59. Domitrovich A.M., Diebel K.W., Ali N., Sarker S. and Siddiqui A., Role of La autoantigen and polypyrimidine tract-binding protein in $\mathrm{HCV}$ replication. Virology 335: 72 86, 2005.

60. Pietschmann T., Lohmann V., Rutter G., Kurpanek K. and Bartenschlager R., Characterization of cell lines carrying self-replicating hepatitis C virus RNAs. J. Virol. 75: 12521564,2001

61. Herold J. and Andino R., Poliovirus RNA replication requires genome circularization through a protein-protein bridge. Mol. Cell. 7: 581-591, 2001.

62. Zhang X., Li H.P., Xue W. and Lai M.M., Formation of a ribonucleoprotein complex of mouse hepatitis virus involving heterogeneous nuclear ribonucleoprotein $\mathrm{A} 1$ and transcription-regulatory elements of viral RNA. Virology 264: 115-124, 1999. 